\title{
5 \\ Landscapes of Accountability in Care
}

As I have demonstrated through the cases of Pendo, Zuhra, and Sarah in the previous chapter, women and their families interpreted stillbirth in multiple ways. Providers and women imbued this unfortunate event with different meanings that then had different consequences for their projects of constructing morality, responsibility, and accountability across different levels. This makes stillbirth a perfect case study for accountability and responsibility, particularly because stillbirths are much more common than maternal deaths, both at Mawingu and globally. Stillbirth and the partograph from the previous chapter demonstrate how the hospital staff and administration constructed alternative avenues for assessing morality and ethics in the absence of a formal disciplinary mechanism. They were often understaffed and lacking many of the crucial supplies needed for their ideal, best practices of maternity care. These struggles, combined with the larger biobureaucratic system's imposition of standardized rules and guidelines for disciplinary proceedings, documentation, and data collection, necessitated ethical and moral negotiations that invoked and depended upon a particularly Tanzanian form of everyday ethics of caring. Faced with constraints and a lack of usable formal routes for discipline and accountability, the maternity ward at Mawingu demonstrated an ethics of care that generated robust but subtle informal accountability mechanisms. Some of the descriptions in this chapter may be disturbing. The language reflects that of the nurses and doctors in this setting.

\section{STILLBIRTHS, BOTH FRESH AND MACERATED}

Pendo and Zuhra's cases illustrate the ongoing challenges facing the health care system in Tanzania. Work environments were characterized by scarcity of people and supplies, as well as sometimes poor communication practices and few routes for holding health care providers accountable for mistakes due to bureaucratic and structural constraints. Stillbirths were a particularly grim consequence of 
these challenges. While Tanzania made progress on the Millennium Development Goals related to reducing child mortality, on some other indicators the country did not fare as well, including "poor progress in reducing stillbirths, with around 47, 550 stillbirths per year, of which $47 \%$ are intrapartum, which is a sensitive indicator of poor-quality care at birth" (emphasis added). ${ }^{1}$ This statistic indicates that the challenges leading to stillbirth were not confined solely to hospitals such as the Mawingu Regional Hospital but were occurring throughout the country.

Different types of stillbirths brought with them different quandaries and speculation about causes and responsibility and carried different implications for providers and the hospital. Pendo's stillbirth was intrapartum, what the nurses and doctors at Mawingu called a "fresh" stillbirth, and fresh stillbirths were often related to provider skills or lack thereof. "Macerated stillbirths," another classification, were displaced onto other forces. This type of stillbirth, macerated, received its name from the appearance of the baby, who had usually died sometime prior to birth, an intrauterine fetal death, most times of unknown cause. The baby's flesh was often mottled, peeling off, or necrotic, and sometimes the small body was severely misshapen. If it was in an advanced state of decay, women were at a heightened risk for infections. These births, the delivery of a macerated stillbirth, often took much longer, ${ }^{2}$ and they were emotionally, as well as physically, difficult for both the mother and the nurses involved in assisting the woman. Sometimes the woman had to stay lying on her back for hours while the deceased baby's body was partially protruding from, but not fully expelled by, her body. Instead of the nurse making the quick, deft movements that often freed the living baby at this stage, both mother and midwife steeled themselves for the tortuous process of emergence of a being who had long since ceased to live. However, there was never any talk of who was to blame in these cases; it was generally accepted that the fetus had died of unfortunate causes, natural or otherwise, that were unrelated to the actions of the providers at the health facility.

\section{ACCOUNTABILITY AS VIEWED FROM THE OUTSIDE}

People working in NGOs and in the government on maternal and neonatal health projects and policies told me they thought nurses fabricated the state of stillborn babies, writing down more macerated stillbirths than "fresh" as a way of protecting themselves and producing statistics that showed their facility in a more favorable light. Here, once again, providers were seeking to comply with the demands for documentation of improvement, as well as complying with national, and global, demands for data collection. However, they were subverting the original purpose of these data collection initiatives by fabricating outcomes and events, thereby throwing into question all data produced by similar facilities throughout the country.

I did not have to look even to people outside the maternity ward for this insinuation about "cooking" data. One of the nurses in charge told me quite frankly that 
she was convinced her subordinates were writing down babies as macerated when they had not been. Nurse Alvina had been in Pendo's surgery and commented that she thought the baby was macerated, an observation that would have shifted the responsibility for the baby's death away from the ward staff and onto other forces, before Pendo's arrival. Differing interpretations of whether a stillborn baby was fresh or macerated could have accounted for many of the misattributed stillbirths. After all, how mottled and necrotic does a baby have to be to be macerated? Sometimes it was abundantly clear, as when the small body oozed fluids and the skin easily peeled off, but other times the distinction was rather less easily made, and the nurses had to use their best judgment to decide how they should classify the baby. Rather than reading the nurses' actions as necessarily duplicitous, and suggesting nurses were purposefully trying to fabricate the numbers, we might conclude that perhaps sometimes it was simply a matter of different interpretations of the state of the stillborn baby's body. Nurses with more training or experience would have been able to more accurately differentiate between a truly macerated stillbirth and one that was more borderline fresh. Regardless of the degree of interpretation required, the bottom line was that nurses had an incentive to conceal fresh stillbirths, which would reflect poorly on the care they had been able to provide. With Pendo's baby, it was unlikely that Nurse Alvina was right about it being macerated because less than twenty-four hours before her C-section Pendo's baby still had a heartbeat. Usually it took much longer for the fetus to begin to decompose in utero.

Certainly, the nurses and doctors would have all liked to see a reduction in the number of fresh stillbirths, but it was easier for them to switch their priorities to accounting for poor care by concealing the true number of fresh stillbirths, or by hiding partographs that would indicate neglect or other wrongdoing, than to fundamentally change their operating procedures. This was, at least in part, due to the difficulty they encountered on the procedural, administrative, and bureaucratic levels every time they sought, as a ward, to initiate changes. Such resistance from individuals and the system further disincentivized efforts to improve outcomes and reduce deaths. At the hospital level, a real commitment to fundamentally improving care in order to reduce intrapartum stillbirths would have required prioritizing maternity care and investing in continuing education, mentoring, and supervision. All of these needs would have been inconvenient, as well as simply unsustainable because of budget limitations and lack of personnel.

At a higher level, the central government would have had to make the fundamental shift in perspective that these lost children, and their mothers, were a priority for investment. As of yet, this does not seem to be the case. As one Ministry of Finance employee told me, the government has the resources, and if they decided to prioritize maternal care, no more women would die from pregnancy-related causes. It is simply that the government does not yet have the will to make this problem a greater priority. 
In the context of everyday life on the Mawingu Regional Hospital's maternity ward, accountability comes to take on at least two different meanings. First, the term can be thought of in relation to accounting for money-aid, investment, resources, supplies, equipment. ${ }^{3}$ Second, it can mean being accountable, as in being subject to report, explain, or justify actions (or inaction). I primarily use it this way on the personal, instead of fiscal, level to talk about providers' responsibility for care or other tasks in the biomedical setting. Providers talked about being accountable to themselves, to their superiors, to patients, to their profession. In turn, the hospital is accountable, at an institutional level, to the central government. As public sector employees, all health care workers are also responsible to the government, their employer. In a public health landscape in which NGOs and foreign organizations appear to dominate and drive policy, the state still plays a vitally important role as the employer of most health care personnel in the country and as a builder of health infrastructure. ${ }^{4}$ Because health care workers were agents of the government by way of their employment, when community members tried to hold them accountable for care they were also attempting to hold the state accountable.

A bevy of global organizations (the World Health Organization, the International Monetary Fund, the World Bank), NGOs, and foreign governments, which donate funds to the health sector, hold the central government accountable for expenditures and advancement toward achieving health indicators. ${ }^{5}$ With the expansion of NGOs, direct budget contributions, and other forms of foreign aid and assistance to countries like Tanzania, these organizations have demanded increased accountability in a number of ways while often escaping it themselves by circumventing state structures or providing parallel systems within state structures. ${ }^{6}$ In the end, especially as government employees, the providers at Mawingu were also accountable, by extension, to these other actors who imposed conditions on monies or pushed policies and protocols.

\section{FORMAL SYSTEMS OF ACCOUNTABILITY}

Despite this ascending pathway for accountability, the formal, government systems for reporting a health care worker's mistakes or negligence were circuitous and prolonged, working to put off the actual moment of discipline. Supervisors could not initiate the formal disciplinary procedures unless a patient or her relative made a formal complaint. Dr. Joseph, the medical officer in charge, told me that even if women and their relatives suspected something had gone wrong with the care at the hospital, they almost never moved beyond suspicion to make a formal complaint.

Sitting in his office one bright afternoon, as the cool dry-season breeze pushed in through the half-open window, Dr. Joseph told me with frustration, "Sometimes they know something has gone wrong here in the hospital with their relative, but they come and tell me, 'I don't want this person punished, I just want you to 
know what is happening in your hospital.' What can I do then with that information if they refuse even to go on record with their complaint?" He went on to explain that it was not easy for him to initiate disciplinary proceedings without these formal complaints against a provider. The fact of the matter was that the Tanzanian Ministry of Health and Social Welfare had strict guidelines and protocols for disciplining health care providers that, because of their complexity and lengthy proceedings, resulted in excellent job security for government health care workers. Dr. Joseph explained this situation further, giving these disciplinary procedures as an example of how the bureaucracy above him, over which he had no control, affected how he was able to work:

Some of them [health care workers] completely misbehave, okay, but I cannot take action. I would comment that this person is misbehaving, but I have to start with a lot of issues; say, okay, from the department, make sure you document his mistakes, and thereafter, when you feel like now you are tired, you bring it to me. I have again to sit with him, discuss once, twice, or thrice. From there, and then I have to give some warnings-verbal, then written, then thereafter I cannot say, "Now! You're fired!" I have to recommend that "I have this employee who had so and so, please take action against him," or I just bring him before you for your attention. And then you will decide. Yeah? And then you will decide, whether to take action or not. You see?

In these formal proceedings, the people who would ultimately decide the fate of the employee in question were the regional medical officer (RMO) and, as the last step, the regional administrative secretary (RAS), who was responsible for the hiring and firing of all government employees in the region. What most often seemed to be the result of these procedures, if they were even initiated, was the transfer of an employee from one department or post to another in which Dr. Joseph or the nursing administration felt he or she would be able to do less damage. For example, while I was present, one lab technician was suddenly moved to the Medical Records Department and then to the mortuary. The prevailing rumor was that he was constantly drunk while at work and that the hospital leadership, being unable to fire him, had transferred him to departments in which less expertise and specialized competency were necessary. Speaking generally, Dr. Joseph told me that he had recently been dealing with an employee who had been unable to fulfill his duties but whom he was unable to dismiss. He was continuing to look for how the situation might be best resolved to protect patients and the other staff members who might rely on that provider.

These proceedings were easier to initiate if, as Dr. Joseph mentioned in the start of our conversation, a patient or relative came forward. If this occurred, Dr. Joseph could also launch an investigation through the offending provider's licensing body, the national nursing or medical organization. But community members' reluctance to come forward was often also partly due to strong cultural norms related to not embarrassing others, maintaining smooth social relations, and saving face. Other 
researchers have documented this same preference and face-saving ethos in other East African settings, ${ }^{7}$ but it has a long history for Fipa people specifically too. In precolonial Ufipa, there was a woman specifically in charge of levying fines against people who engaged in a certain class of offenses, including verbal obscenity. ${ }^{8}$ Sanctioning those who engaged in these forms of public obscenity was an important mechanism for the Fipa to maintain their ideals of intensive social interaction that was also courteous, thereby preserving social cohesion. ${ }^{9}$ This female-led system no longer exists. But in the present day many patients and their relatives preferred not receiving redress-even in the form of an apology-for suffering, neglect, or malpractice when the only route to redress was through the act of naming a negligent provider or initiating a case against him or her.

In other settings, families might resort to the court system to hold health care workers to account. But the medical malpractice legal landscape in Tanzania remains largely undeveloped. ${ }^{\circ}$ In 2015, a woman and her husband did successfully win a case against a doctor whose mistakes during a C-section left her struggling with permanent infertility. ${ }^{11}$ In 2013 , a medical student told me of a case of a malpractice suit brought against a hospital and health care workers in the Kilimanjaro region of the country, one of the wealthiest regions with a highly educated populace. A lawyer working for the prime minister's office was unable to provide me with any further information about this field of law in the country. ${ }^{12}$

There is evidence that malpractice litigation in health care skews scarce resources further toward those who can already access them, withholding important care from more marginalized segments of the population. ${ }^{13}$ Additionally, John Harrington argues that the colonial and socialist history of Tanzania has resulted in "no widespread perception of litigation as a means of providing for the accountability of the agents and institutions of the state-including the great majority of medical professionals who worked for it."14

At Mawingu, in any instance of mistakes in patient care, the nursing administrators and the ward nurse in charge usually met privately with the person who had made the mistake. These values related to minimizing public embarrassment were integrated into the hospital's management style at all levels. The social value placed on minimizing conflicts and not directly accusing others of wrongdoing, combined with a lack of other providers, and a legal landscape that did not easily facilitate malpractice litigation, made it especially difficult for families to come forward with accusations of neglect or complaints about bad care. Families already lacked power and authority within the biomedical system, and this further intensified their hesitancy.

I came to know the medical officer in charge to be a man who often, if not continuously, thought about ways to elicit the complaints and grievances of clients and their families in order to improve the care his hospital offered. In other discussions, Dr. Joseph confided that he wished someone would encourage a patient who 
had been wronged to come forward with a formal complaint, demanding some form of restitution for, in these types of cases, the loss of their child. He suggested that even one such legal case against a provider at the hospital would awaken all the providers anew to their responsibilities, hopefully making them more careful and compassionate in the future. In the absence of formal accountability structures that would actually be able to hold health care workers immediately responsible for mistakes or lapses in judgment, the hospital's bureaucratic, institutional environment fostered the growth of robust informal systems of accountability based on the negotiations of everyday ethics of concealing or revealing mistakes. Brodwin argues that the real-world effects of everyday ethics are rarely lasting because of the constraints limiting implementation of imagined changes. ${ }^{15}$ While this was true in many other instances, in this case, at Mawingu, everyday ethics, the moral and ethical convictions of the health care workers, but also those of the community members reluctant to accuse providers, led to the very real creation of profound and durable, though fluid and sometimes hidden, informal systems of accountability.

\section{INFORMAL SYSTEMS OF ACCOUNTABILITY}

Much like Pendo, Zuhra delivered a stillborn baby because of the rupture of her uterus, caused by similar lapses in communication and gaps in care after her arrival on the maternity ward at Mawingu. Zuhra's case serves as another example of how women, their relatives, and the hospital staff struggled with the consequences of stillbirth and issues of accountability. In Zuhra's case, the family told me they did not believe it would even be useful to complain. They were, instead, resigned to the hospital's status quo and lacked faith in the hospital administration's ability to create change within the institution. Zuhra's relative, who was a nurse, intimately knew the administrative workings of the hospital and told me, "I know exactly what went wrong. Even she did not get the units of blood she was supposed to. But what can we do?" I suggested she file a formal complaint, and she responded, "What would happen anyway? No, it is not useful." I also suspect she may have been concerned that doing so would affect how her fellow staff members and superiors at the hospital perceived her.

Reporting on the mistakes of one's fellow providers was not well received, and one nurse told me it was common to not report mistakes unless the administration somehow found out about them. Nurses instead preferred to protect each other, giving colleagues a chance to mend their ways before superiors found out about their misdeeds. Nurse Peninah explained to me,

If the employee makes a mistake, the first thing, if she hasn't already gone to Patron, or to the [ward nurse] in charge, you find that we ourselves, if we are there on the ward, we'll sit and tell each other, "Man, here we messed up, you did this, but let's do 
this." And if you see that it's not entering [into a person's head], what they should do, you find that other people will tell the in charge that "this person is like this and this and this and we have been there with her." The in charge will call her personally. You see? The in charge, if she isn't able to handle the person at all, then she goes to the leadership now. But things like that take place rarely; really everyone stops here. $\mathrm{Bu}$ now, you find those things that have been called by Patron there, either a person went out from [the ward] and they have gone to tell about it there, or Patron himself has arrived here and encountered someone doing something and called them there [to his office]. But, many times, you find that the issue is finished here, here inside. Maybe only if a person is really violent or argumentative [the issue goes to Patron].

Peninah's description shows the informal ways in which the maternity ward nurses worked to regulate themselves and their colleagues in order to keep their ward issues within the family, so to speak. The maternity ward drew enough criticism and negative attention as it was; they did not also need to bring down further criticism for their mistakes. These sorts of self-regulatory mechanisms also helped to maintain smooth social relations among the nurses on the ward and reduced conflict between management levels within the hospital. If Zuhra's nurse relative had gone to the hospital management to complain, she would have been breaking ranks with the other nurses at the hospital and jeopardizing her own social position and, subsequently, the social capital she needed to accomplish her daily work. These implications of reporting suspected problems deterred Zuhra's relative from coming forward with a formal accusation.

Peninah's comment about the infrequency with which issues were called to the patron's office suggests that for a maternity nurse to report directly to the patron was a violation of an unspoken agreement the nurses had to keep their problems or mistakes to themselves, to protect themselves professionally and socially. But this standard way of handling mistakes among the nurses also was a reaction to the patron himself and the administration more generally. Past interactions with the hospital administration had demonstrated to nurses time and again their low position in the institutional hierarchy. Administrators nearly always prioritized the accounts of physicians and patients' relatives over those of the nurses until an inquiry was initiated and the nurses were brought into a meeting to account for the details of a case. In these meetings, the nurses would repeatedly assert their innocence, often in opposition to the accounts of lay people (relatives) who were not present in the meeting but whom the nurses portrayed as confused and unable to understand the complicated biomedical institution. Usually any complaints against the staff members that moved beyond simply notifying an administrator were mediated, and the hospital administrators preferred to sort out the sequences of events in meetings, the findings of which were relayed back to the people who had made the complaint. I saw this happen particularly regarding the availability of supplies, and it was most often simply due to misunderstandings or miscommunication on both sides, as opposed to what might be termed malpractice. With 
these interactions in mind, it is no wonder the maternity nurses had little trust in their superiors and sought first to deal with mistakes among themselves by enacting a more informal system of accountability.

\section{ACCOUNTABILITY, LANGUAGE USE, AND THE MAKING OF MORALITY AND ETHICAL RESPONSIBILITY}

Even in Pendo's case, in which the nurses and doctors admitted neglect, they skirted around the issue of blame, and there were no direct consequences for the providers' actions or lack thereof. The medical officer in charge told everyone gathered in the meeting regarding her case, "So in fact ... there isn't a person who is going to come here to take action against you, nor will we write you a [disciplinary] letter, now we will not do anything." In the same monologue, not only did Dr. Joseph touch on communication, handover practices between shifts, disciplinary procedures, the trust patients had in the hospital's services, motivation, and staff scarcity, but also he spoke in a pained manner about the ethical and moral consequences of staff's collective (in)action in Pendo's case. Certain pervasive themes arose in all aspects of my participant observation and interviews. Here, Dr. Joseph invoked all these themes at once in an attempt to motivate his staff to work for improved care. His rhetorical techniques also aimed at awakening the nurses to the repercussions of their actions and care for the women and families directly affected.

In an earlier effort to convince the nurses to sympathize with Pendo and other, similar, patients, Dr. Joseph used two metaphors about why a health care worker might be insensitive to a pregnant woman in her care. In the first, he suggested that people without children might be jealous and resent other people having children, thereby preventing them from doing so. He compared the person without children to someone who wants the 10,0oo shilling bill that another person has. One bill can't be shared, so the person who wants the bill tears it in half out of irritation and spite so that neither person can have it, the torn bill not being legal tender. In the second metaphor he said, "Second scenario, me, I have money, or isn't that right? Yes. Therefore, you don't feel the pain of a person that doesn't have money, okay? So similarly, you have a child, you don't see the pain of a person that doesn't have a child. You think, like, a baby, you can go to the market and buy a baby, and so you are being comfortable." For those health care workers on the ward who had never struggled to have a child, Dr. Joseph was insinuating that they might take for granted the ease with which they started a family, just like going to the market, and that this might cause them to overlook the pain of those who had struggled and desperately wanted the child they were carrying.

Within Swahili speech patterns, metaphor is very common. In the most practical sense, speakers often employ metaphor to criticize another party. The use of metaphor is crucial for the social act of saving face because the veiled nature of the 
criticism leaves room for the speaker to remove him- or herself from the criticism and creates a space for the listener to not understand the veiled implications. ${ }^{16}$ Here, the thinly veiled criticism was that a nurse's personal problems-jealousy because she herself had no children or callousness because she now had them and had forgotten the struggles or hopes of those who did not-might cause her to neglect her duties, even if not from some actively malicious intent of which she was aware.

Dr. Joseph also drew on religion, something to which all the nurses and doctors told me they ascribed, as well as humane practice ("Humanly, it's not acceptable," using the Swahili word kiubinadamu, which is derived from the word for humanity), and invoked the nurses' own childbearing or reproductive pasts. Left without an official avenue through which to discipline his staff, Dr. Joseph instead entreated the maternity ward nurses, telling them,

But me, I'm telling you, if we continue on this way, you should all really know that this heaven, it's there, just we aren't going there. We help a lot of people, but we will do just one mistake and we won't go there, there, where all those who believe in God should go, but even if we don't believe in God, humanly [as humans] it is not acceptable. Therefore, I saw that I should deliver this message, that let's just not continue this way or we see that there is no punishment that we can get and we just do that, but it's not a good thing. Why should you not do something [only because] you will be punished?

In the last sentence, he was trying to center the responsibility for the events squarely on the nurses, instead of employing other rhetorical devices to provide them with a more comfortable distance from the neglect and negligence. He went on to tell them that they should make changes in the way they thought of patients and that they should share reports, particularly during shift changes, so that they did not forget any patient again in the way they had forgotten about Pendo. He encouraged them to focus on providing good care, not simply preventing badtwo very different goals. No woman should become lost in the shuffle of the busy ward, as had happened to Pendo and her baby.

In an effort, once again, to impress upon the nurses the gravity of the situation, Dr. Joseph told them, "I had already finished writing my lie here 'poor progress of labor', and I conclude ${ }^{17}$ [it was due to] . . . but I'm protecting people here. You all should know I'm doing it because I don't want it to get out of our hands, out of this house, okay? But I'm sure, me, I'm taking on another sin for writing a lie, and I vowed that I shall not relay this, but, friends, if we do this, it is not good." In this last reprimand, his open transparency about his actions was a shift away from veiled, metaphorical language as he tried to make an example of himself. Again, in the repetition of "sin," Dr. Joseph used language heavily laden with religious significance, his particular frame of reference for morality. Before studying to become a doctor, he had started studying to become a priest and was still, when I met him, 
an observant Catholic. Those nurses who knew him, as well as those with strong personal religious beliefs, would have been duly chastened by this implication of sin that could jeopardize not just their earthly life but the one they hoped would follow after.

In these attempts to impress upon the nurses the gravity of the situation, we can see what Michael Lambek so aptly refers to as "living the gap," or "what it means to live in a world with ideals, rules, or criteria that cannot be met completely or consistently." ${ }^{18}$ It is in this gap that we find everyday ethics, when people like Dr. Joseph "must revisit other deeply held priorities concerning the good, the honorable, and the obligatory." ${ }^{19}$ The medical officer in charge often struggled, in a deeply personal way, with the constraints of the bureaucratic system in which he worked and the ways they prevented him from enacting his highest ethical standards of patient care and discipline. Instead, the system itself increased the probability of poor service or more extreme cases of neglect, such as Pendo's. And it is of the utmost importance to remember that these cases arose, not simply from personal faults of individual providers, but from clashes of many groups of people and facilities with far mightier institutions. Financial, medical, and sociocultural processes and institutions shaped and limited how the nurses and doctors came to be able to practice care in the Mawingu Regional Hospital; these constraints shaped what was or was not possible in the practices of care and, by extension, shaped the very meanings of ethical caring in this setting.

Dr. Joseph also told the nurses in the meeting about the stillbirth of Pendo's baby that even if they made mistakes, mistakes were not a reason to stand on the sidelines the next time they encountered a difficult case. Instead, each nurse or doctor was responsible for putting forth his or her best efforts to care for patients and additionally responsible for reminding colleagues to complete tasks such as documentation. Here again he was attempting to impress upon his listeners, the nurses, that they were responsible not only for their own actions but also for the actions of their colleagues and that everyone was collectively accountable for the care the hospital provided to patients. These ideas about collectivity and collective accountability may not be unique to this particular health care system. We might expect to see such in-group cohesion in any system in which a group must work closely together. However, in the context of Tanzanian, and more broadly African, ideas about interconnectedness and collective decision-making and living, Dr. Joseph's entreaty takes on even greater significance. This collective accountability is one of the most significant aspects of a particularly Tanzanian ethic of care, different from what might be found in health care institutions peopled by workers from a different philosophical origin, outside of a deeply embedded Afro-communitarian way of being.

In a divergent manner of speaking about the tragic stillbirth, Nurse Gire asked to make a statement before they concluded discussing Pendo's case. She said that those gathered (she was specifically referring to the maternity ward staff) should 
also acknowledge the good work they do, and she proposed the "compliment sandwich" in which you deliver good news, bad news, good news, always making sure to end on an encouraging note. She then proceeded to say:

Those challenges, what do they do? They stimulate you all to build yourselves anew. This case is a challenge. I think, now, it has already balanced us, if we were already starting to slack off. . . . It's necessary for there to be challenges so you all do well. Don't depend on it, that every day you will do everything well, this philosophy doesn't exist. Therefore, take the challenges as challenges and let us not be content for them to repeat and repeat themselves. If it happens through bad luck, like these, we can't avoid bad luck, friends. To break a cup, aren't you holding it? You want it not to break but you find that it slips away from you.... Therefore, challenges like these, let us accept but let us not entertain them [happening again] apart from accepting them. (emphasis added)

Gire was involved in Pendo's care from the very beginning, but though she clearly stated, earlier in the meeting, that staff had neglected Pendo, she did not use the same impassioned rhetoric as the medical officer in charge, Dr. Joseph. Gire's comments were much more representative of how providers commonly discussed stillbirth. Instead of calling these events a tragedy or sin as Dr. Joseph had, Gire used the much more neutral term challenge (changamoto), which speakers often employed throughout my time at the hospital to present areas for improvement when they did not wish to use the more negatively construed word problems (matatizo). In her comments, Gire also used a metaphor to convey the inevitability of "bad luck" (bahati mbaya), which was likely to befall the ward from time to time. Her use of metaphor here may have had the same face-saving application, as well as bolstering the ward's collective identity once again, after Dr. Joseph had worked hard to individualize the nurses present by confronting them with the moral peril in which they stood. Gire's much different tactic was also a poetic way of reassuring her colleagues that they needn't feel too bad for what happened to Pendo; perhaps she was seeking to improve morale so they could all face the day's work.

Gire's use of the term bad luck is especially significant here. At no time in the discussion of the case did either of the doctors use bad luck as a way of explaining what had happened. They were much more clearly focused on dysfunction in the ward, particularly as related to documentation and communication practices. Dr. Joseph and Dr. Deo, in all of their comments, clearly laid responsibility for the death of Pendo's child at the feet of the nurses and, more generally, the maternity ward staff. Gire, whose comment was the last in relation to Pendo's case, displaced some of the blame from the nurses. By using the term bad luck, she very clearly was acting to move responsibility and blame onto other, less controllable and more indeterminate forces.

Gire's use of bad luck was much more similar to that of Pendo and her mother-in-law, discussed in the previous chapter. The term drew upon feelings of 
resignation regarding events that had long been common experiences for women and families in their childbearing years. This resignation was a usual response for women and their families, who might not have shared health care providers' exposure to or belief in the authoritative biomedical explanatory models or might not have experienced other possibilities for pregnant women. But when the nurses, who were trained in the management of difficult births and abnormal deliveries, employed the term bad luck, it was not in the absence of other ways of understanding the event. It seemed, therefore, to be a way to shift responsibility and blame away from themselves and onto larger, more diffuse forces during these tragic events.

Likewise, nurses often referred to stillbirths as "missing" the baby (amemiss mtoto). This term is a bit more difficult to decipher and, while clearly a carryover from English, could mean something very different in another context, as when the speaker might mean the woman "missed" her child (because she had not seen the child in a long time, etc.). This construction is also a particularly interesting way to disembody the actions or events that led to the stillbirth, simply suggesting the woman "missed" her baby the way one might "miss out" on an opportunity, with no apparent locus of control or responsibility.

When providers, patients, and their family members called neglect or malpractice "bad luck," whether or not they believed this to be true, they were effectively enabling providers to continue to evade accountability and responsibility for their actions, part of a broader bureaucratic and systemic challenge regarding accountability. The Tanzania Nurses and Midwives Council's Code of Professional Conduct for Nurses and Midwives in Tanzania clearly states in section 4: "The nurse and midwife is responsible for maintaining professional standards for quality care and [must] be accountable [sic] for her action. Therefore, she shall observe the following: . . . 4.3 accountability for her actions or omissions through formal lines of authority and responsibility, 4.4 respecting and complying with rules and regulations in a manner that promotes public confidence, the integrity of nursing and midwifery services and profession" (emphasis added). ${ }^{20}$ However, the question the medical officer in charge wrestled with nearly every day was how nurses could be held accountable through formal lines of authority and responsibility in meaningful ways when the government and Ministry of Health had effectively constructed disciplinary procedures that were so bureaucratic and prolonged as to be nonthreatening and absolutely ineffective.

In an effort to provide a framework for ethical action and caring in the absence of easily accessible formal mechanisms for enforcing sanctioned ethical standards, the medical officer in charge drew on his own moral values. In a singular manner, he tried to embody and convey the moral and ethical physician who takes responsibility for his actions, even as he lives the gap. Despite being unable to initiate a case against the nurses on account of bureaucratic constraints, he reflected on how 
his actions (or lack thereof) eroded his moral scaffolding. The way the hospital treated Pendo shook the foundations of goals he valued, such as the ultimate goal of reaching heaven, and his responsibilities to his patients. In the absence of formal lines of authority and responsibility to ensure ethical and moral conduct, Dr. Joseph was attempting to construct another avenue for impressing upon his staff how unacceptable their actions had been. Were his words weakened without the force of concrete disciplinary consequences behind them? Perhaps. However, through his rhetoric he was embodying the caring physician who was deeply wounded by this neglect of Pendo. My interpretation of part of the reason why so many of the hospital staff members respected and liked Dr. Joseph as the medical officer in charge was that he was not afraid to face these types of cases head on and was a genuine person as well as an authentic leader. In his discussion of Pendo's case, he did not simply yell at the nurses, reprimanding them for their inaction or incompetency, but put himself into the conversation, placing his moral being on the line together with theirs.

In the regional hospital's labor and delivery room, nearly every morning I was met by the tiny bodies of stillborn babies lying on a table near one of the doors (figure 12). These bodies were perhaps the best indicator of how well a particular shift performed, how skilled a labor ward was, or how well equipped physically the ward was. I could always tell if it had been a good or bad night by the number of bundles present on that table. While Dr. Joseph passionately discussed what had gone wrong in Pendo's case and was transparent about how he had tried to cover up wrongdoing and neglect, most stillbirths did not draw a similar level of attention and discussion. Instead, nurses and families referred to "bad luck," which allowed the nurses to avoid addressing the underlying problems in their department and on their ward.

Several health care providers, working both within and outside of the government health care system, told me they sometimes felt health care providers and administrators were reluctant to straightforwardly name and discuss problems and that this made it difficult to address these issues and improve care, their ultimate goal. Instead of simplifying the tangle of bureaucratic communication and documentation practices to ensure that women did not slip through the cracks, nurses and doctors sometimes changed diagnoses, intraoperative findings, and partographs to hide evidence of substandard care to further other goals related to their everyday ethics of care in their setting. These everyday ethics of care relied heavily upon collectivity and the ward's internal social cohesion. Sometimes, as in Pendo's case, many providers were complicit and knew of the mistakes that had occurred. However, in other cases, an individual nurse might have made a mistake and, fearing confrontation with either the patient's family or the nursing administration should her mistake become known, would hide the evidence of her error. Because of the shortage of resources, which extended beyond the sole control of 


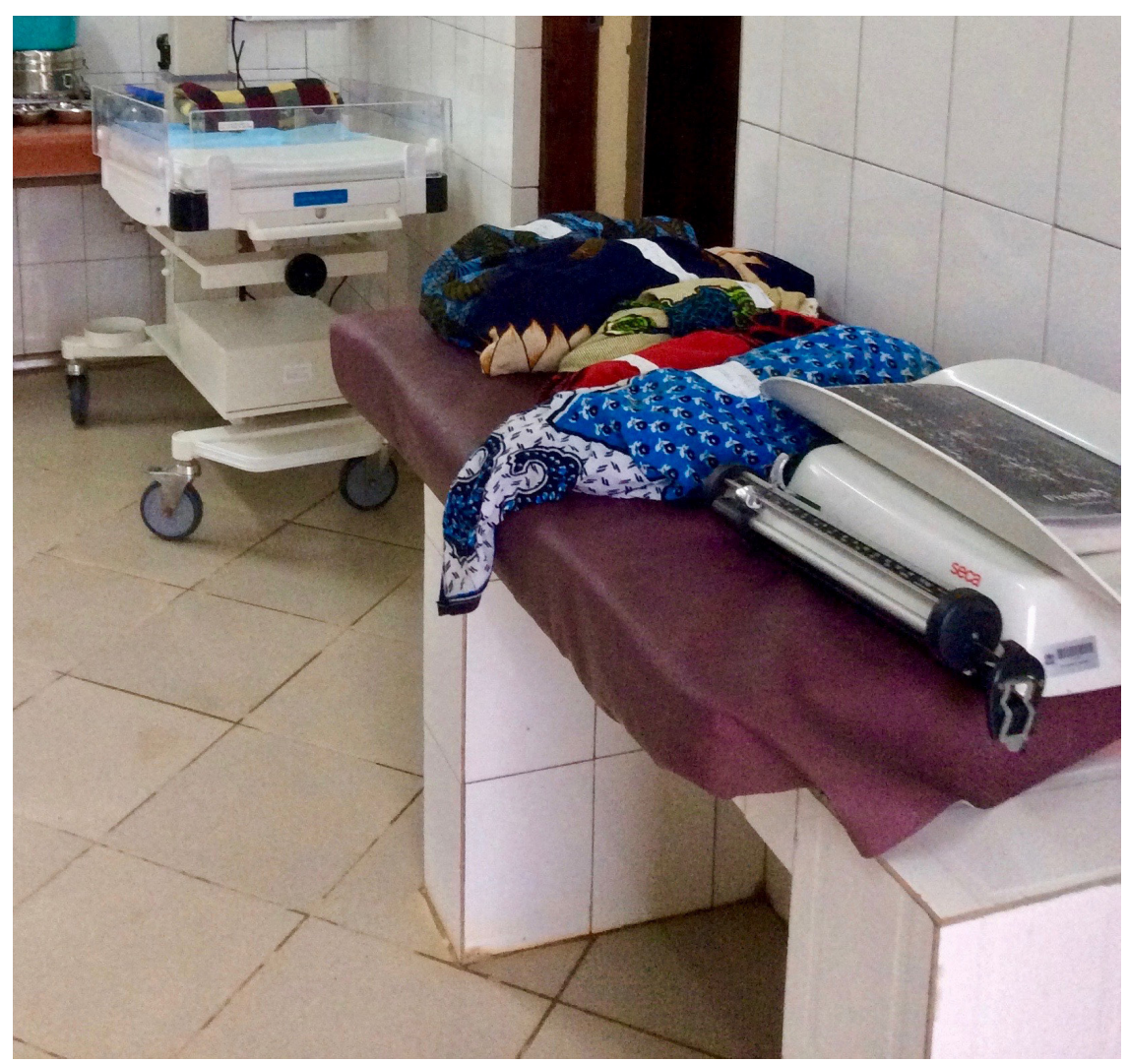

FIGURE 12. Five bodies of deceased babies lying on a table in the maternity ward of Mawingu Regional Hospital. Photo by author, 2015.

the hospital to regional and national levels, providers were often severely limited in what they were able to accomplish in terms of meeting the externally imposed guidelines for best practice.

In the absence of disciplinary threats or recourse, informal mechanisms of accountability, as well as tampering with evidence via disposing of important documents, were social acts meant to prevent criticism and embarrassment of the ward's staff members, thereby ensuring smooth social relations in this highly interdependent community of nurses and doctors. Additionally, social ideals about not losing face and not causing others to lose face (particularly through public embarrassment and criticism) may have dissuaded patients from making formal complaints and led to discipline being impossible. This impossibility was further ensured by strict and convoluted bureaucratic guidelines for dispensing warnings and disciplinary action within the government health care sector. All of these processes contributed to a system that did not easily adopt changes to 
routines. Instead of receiving acknowledgment of wrongdoing or medical errors, the patients and their families were left with no real choice other than to engage in the cognitive work of shifting blame once again. They shifted it from themselves onto luck and God in an attempt to come to terms with a tragedy that was still all too common in their communities. Ultimately, patients had no other avenue for coping with these events because of how health care providers, administrators, the system more broadly, and its documentary accoutrements, as epitomized by the partograph, constructed the realities of stillbirth.

In this environment that made change or reformation feel nearly impossible, the nurses and doctors had little possibility of revolutionizing their care practices. Instead, they were swept up into a global system that promulgated the idea that good care was documented care, incentivizing accounting for deviations from guidelines while simultaneously disincentivizing changes in practice that would result in different care for women and babies. Within this system, maternal and neonatal deaths, as well as intrapartum stillbirths, not only could happen but were nearly impossible to avoid. 